Abstract

Professor Brian Findsen,

Te Whiringa School of Educational Leadership \& Policy,

Faculty of Education

The University of Waikato

Private Bag 3105

Hamilton 3240

New Zealand

E-mail: bfindsen@waikato.ac.nz

Learning in later life: benefits and challenges for volunteers and agencies

This article explores the relationship between learning for older adults and volunteerism. It discusses how volunteerism among older adults may enhance their learning and the kinds of benefits and challenges they encounter in their work for employing authorities. Usually, this co-operative arrangement is based on a premise of a "win-win" situation in which the volunteer builds up further knowledge and skills at the same time as the goals of the agency are fulfilled. Yet there are opportunities and constraints which operate in dynamic workplaces wherein the role of volunteer can be marginalised. The article analyses some factors which function as enhancers or limitations for older volunteers in their work and learning. 


\section{Learning in later life: benefits and challenges for volunteers and agencies}

This article is concerned about how volunteerism among older adults enhances their learning and the kinds of benefits and challenges they encounter in their work for employing authorities. In many societies, civil society is strengthened by the willingness of elders to contribute their expertise to varied agencies. (The terms agency or organization are used interchangeably with employing authority in this paper). It is usually regarded as a "win-win" situation in which the volunteer builds up further knowledge and skills at the same time as the goals of the agency are fulfilled. What can be determined about the type and extent of learning for older adults? What kinds of opportunities or constraints do they face in this volunteering process? On the other side, what do employers gain from engaging older people as volunteers? What kinds of benefits do accrue? These questions form the basis for this exploratory research which investigates the inter-connections between older adults' learning and volunteerism.

\section{Who are older adults?}

For the purposes of this article older adults are defined as people 65+ years, an age which is arbitrary but which is quite commonly associated with "retirement" and the award of pensions (Phillipson, 1998). Limiting an understanding to older adulthood to a specific age is problematic, given that life expectancy across cultures varies significantly and the transition from work to nonwork is not necessarily linked to a position in the life course (Findsen, 2005). The notion of the third age, popularised by Laslett (1989) in the UK, has gained credence in most parts of the globe to denote a period in one's life when citizens may be freed from the trammels of work to engage in creative endeavours, often deferred from earlier life. This is an important link with volunteering because many older adults, especially those retired from professions, are freer of commitments to work and family, and have more time to devote to contributing to society.

\section{Lifelong learning in later life}

The concept of lifelong learning has been used globally to capture the fundamental idea that learning accompanies living and consequently is never absent throughout life. While this learning may occur in a range of locations linked to formal, non-formal and informal sites, it is associated with a number of themes. Formal education is usually hierarchical, highly structured and organised, commonly assessed, often credentialed and provided both by government and private institutions. Older adults have generally been relatively invisible in higher education and formal training contexts. Non-formal education, on the other hand, is typically systematically-organised, less often assessed, and occurs in a wide variety of organisational contexts (e.g. churches; workplaces). Seniors have been keen participants of this form of social learning. Informal learning is more incidental, usually without intentionality, and occurs in daily life to a significant extent. In this mode older adults enjoy most of their learning opportunities in varied contexts (Findsen 2006). All three sites of learning have high potential for older adults' volunteering which can be aligned to diverse individual life goals.

In understanding the learning needs of older people it is useful to consider the categorization provided by pioneer educational gerontologist, McClusky (1974):

Coping needs: adults engaged in physical fitness, basic education; economic self-sufficiency 
Expressive needs: adults engaging in learning to develop themselves personally not necessarily associated with a specific goal

Contributive needs: adults wanting to "pay back" to society through helping others

Influence needs: adults feeling the desire to effect social change.

Much of life (indeed, especially later life) is focussed on achievement of the first two priorities. However, as people enter the third age (Laslett, 1989), there is a tendency to want to be more altruistic, to want to make a difference for society, given the finitude of existence. As explained later in this article, volunteerism provides the opportunity to fulfil many of these learning needs.

The literature on lifelong learning can be categorised in many ways. One common approach has been to identify key themes of lifelong learning as follows: learning as an economic imperative; learning as a source of personal fulfilment; learning as a trigger for active citizenship; learning as a mode of social inclusion (Field, 2000; Findsen \& Formosa, 2011). In each of these thematic areas, older adults can function as volunteers and in such roles continue to learn in multiple ways.

In respect to the "learning economy", older adults play a significant part from voluntary to casual to full-time employment. While age discrimination is outlawed officially in many countries, informal discrimination against elders in the workplace persists (Tuckett \& McAulay, 2005). Such discrimination may occur at the point of recruitment, in retention and in appraisals related to job outcomes (Rothwell et al, 2008). Nevertheless, volunteering plays a major role in economic efficiency for organisations, especially for Non-Government Organisations (NGOs). Older people can provide a flexible workforce which can more readily be dispensed with in tough economic times. Many social services are propped up by volunteers through unpaid labour (Lamdin \& Fugate, 1997). Yet this volunteer workforce, many of whom are older adults, is subject to social class, ethnic and gender differentiation. In social agencies it is hardly a surprise that the majority of (unpaid) workers are women from the white middle class - the stereotypical caring role of many women is transferred from the home to work (Arber \& Ginn, 1995). While older adults do not normally volunteer to boost income, their societal function is to sustain the work and continuity of many agencies.

A second strong theme that emerges from a study of lifelong learning and is connected to older adult volunteers is that of personal fulfilment and identity consolidation. Adult education as a field of practice has often lauded the value of learning for its own sake or for the fulfilment of personal aspirations (Knowles, 1980). Too, as Jarvis (2001) points out, this kind of learning helps to enhance our individual and social identity in later adulthood. For many men and an increasing number of women, the loss of identity from full-time work can be rather traumatic. Engagement in volunteering can allow for either a confirmation of previous roles (as when a retired engineer volunteers to assist a transport museum in fixing machinery) or development of new ones, unrelated to previous work.

From a personal development framework, as pointed out by Laslett (1989), older adulthood in the third age provides the opportunity for greater autonomy and choice in learning activities. It is normal for non-formal and informal learning contexts to be more available than formal. There is the chance for the "reflexive individual" (Beck, 1992) to emerge, to illustrate resilience and resourcefulness in an increasingly uncertain world. In terms of the structure/agency dualism, there is scope for the ascendancy of agency in which individuals exercise fuller autonomy in their learning choices. 
A third powerful theme within lifelong learning is that of the promotion of the idea of an active citizen. This notion also connects with dominant policy discourses in ageing of "active", "productive" or "successful" ageing. Active citizenship entails commitment from individuals to an emergent democratic society and to the establishment of effective social networks for the betterment of local and global communities. In this regard, the firming up of social capital among individuals (Putnam 1995) strengthens the fabric of communities. The consolidation of social networks is a primary method of fostering effective social relationships which may translate into economic benefits. Through volunteering, older people help to consolidate a social identity as a result of collaborating with others and to increase their personal knowledge. As active citizens, older people can exercise their legal, social and political rights sometimes in agencies, such as Grey Power, which promote active participation for overt political purposes. Older citizens, given more discretionary time than younger generations, can potentially engage in social movements (e.g. environmentalism; peace) to awaken ideals of community development (Tett, 2010).

Lifelong learning has a remaining important theme, that of social inclusion/exclusion. From this perspective, many older adults engage in learning despite historical social inequalities that have impacted upon them. While older adulthood is often itself perceived as an arena of significant marginalisation (see theories of social disengagement), when coupled with other components of social stratification (gender; race/ethnicity; social class; geographical location), there is often multiple "disadvantage" suffered by senior citizens (Phillipson, 2013). The main thrust of this approach is to encourage greater participation of marginalised older people in society. Within adult education itself, as in the University of the Third Age (U3A), ownership and control of learning has been adopted by older people, revealed in practices of determining their own curriculum (usually based on the humanities and liberal education), more democratic teacher-student interactions, minimal bureaucracy and conducive learning environments (such as a member's house). Yet even in this espoused democratic space, many older people, who do not have the appropriate cultural capital (Bourdieu, 1974), are inadvertently excluded from this older adult educational movement (Formosa, 2000; Swindell, 2000).

In summary, investigation of themes of lifelong learning reveals some persuasive reasons for older people's efforts to learn. In reality, volunteering can provide multiple channels for learning engagement. Seldom is economic benefit a goal of volunteerism but it could be an unintended consequence. Engagement in the work of a social agency may help an individual to acquire an extended social network in which financial opportunity may emerge.

\section{Understanding the changing workplace}

The dynamics of workplaces have become increasing complex as a result of several macro-level forces - national economies in a state of stringency; shifts in population movements related to immigration; neo-liberal political policies; the effects of globalisation; the information technology revolution; super-complex conditions of work (Casey, 1999). Older adults have often been at the margins of the workforce, occupying part-time and seasonal work, frequently more subject to the whims of employers (Findsen, 2014). Some older volunteers will still have part-time jobs to augment depleted financial resources.

The traditional pattern of the lifecourse involving one-stop education, followed by work and leisure in retirement (Riley \& Riley, 1994) has been severely interrupted by the above societal trends. It can 
no longer be assumed that an individual will gain paid work after education; continuing/further education is becoming more the norm across the lifespan rather than the preserve of the few; leisure may still be more possible in later life than in previous stages but increasingly greater numbers of people beyond 65 years are staying in the workforce for multiple purposes. These purposes may include a financial urgency to maintain a standard of living; a passion for continuing work in a favoured professional area; a fear of becoming too domesticated (especially among men). Accordingly, patterns of volunteering in older adulthood are best understood in this ever-changing socio-economic environment in which motivations and external circumstances may change.

\section{Characteristics of volunteering}

Volunteering is a mode of engagement for citizens to invest their time and expertise in a great variety of agencies, many essential to the sustenance of civil society. Civil society is usually conceptualised as the space outside of the state and the marketplace where people have the choice of contributing their time as a voluntary act (Welton, 2005). Volunteering has been defined by Morrow-Howell (2010) as "an activity undertaken by an individual that is un-coerced, unpaid (or minimal compensation to offset costs), structured by an organization, and directed toward a community concern "( $\mathrm{p} .161)$. While volunteerism occurs across all sectors of an adult population, it is very prevalent among elders (Gee, 2001). Sites where volunteers are prevalent include the health industry, social services, faith-based institutions, governance, workplaces and community settings (Milligan \& Conradson, 2006).

\section{Volunteerism in a national context: New Zealand}

Statistics of volunteering are available at multiple levels: International, national, regional and local. Whatever the overall pattern of volunteering in a specific nation, there is considerable variation according to factors such as gender, age, social class, ethnicity and educational status. The figure below illustrates the extent of volunteering across age groups at two quarters in 2014 in New Zealand acquired via the New Zealand General Social Survey (NZGSS). While at that point in time, the highest proportion of volunteers emerged from the 30-39 age group, the percentage of the population in older cohorts (e.g. 60-74) was only marginally behind. Hence, the tradition of volunteering is strong in this country apart from the youngest group. In terms of longer term trends, volunteering is lower during summer months and "the median hours volunteered per month has remained stable at around 10 hours over the last five years" (Statistics New Zealand, GSS, p.2). People with higher levels of education, household and personal income were more likely to have undertaken volunteering. Yet, the context of this volunteering is crucial and statistics on volunteering may be under-estimated for minority groups where it is less apparent to official statisticians. For example, the depiction of Māori participation in volunteering is likely to be skewed towards European norms (Gee, 2001). 


\section{Age and Volunteering}

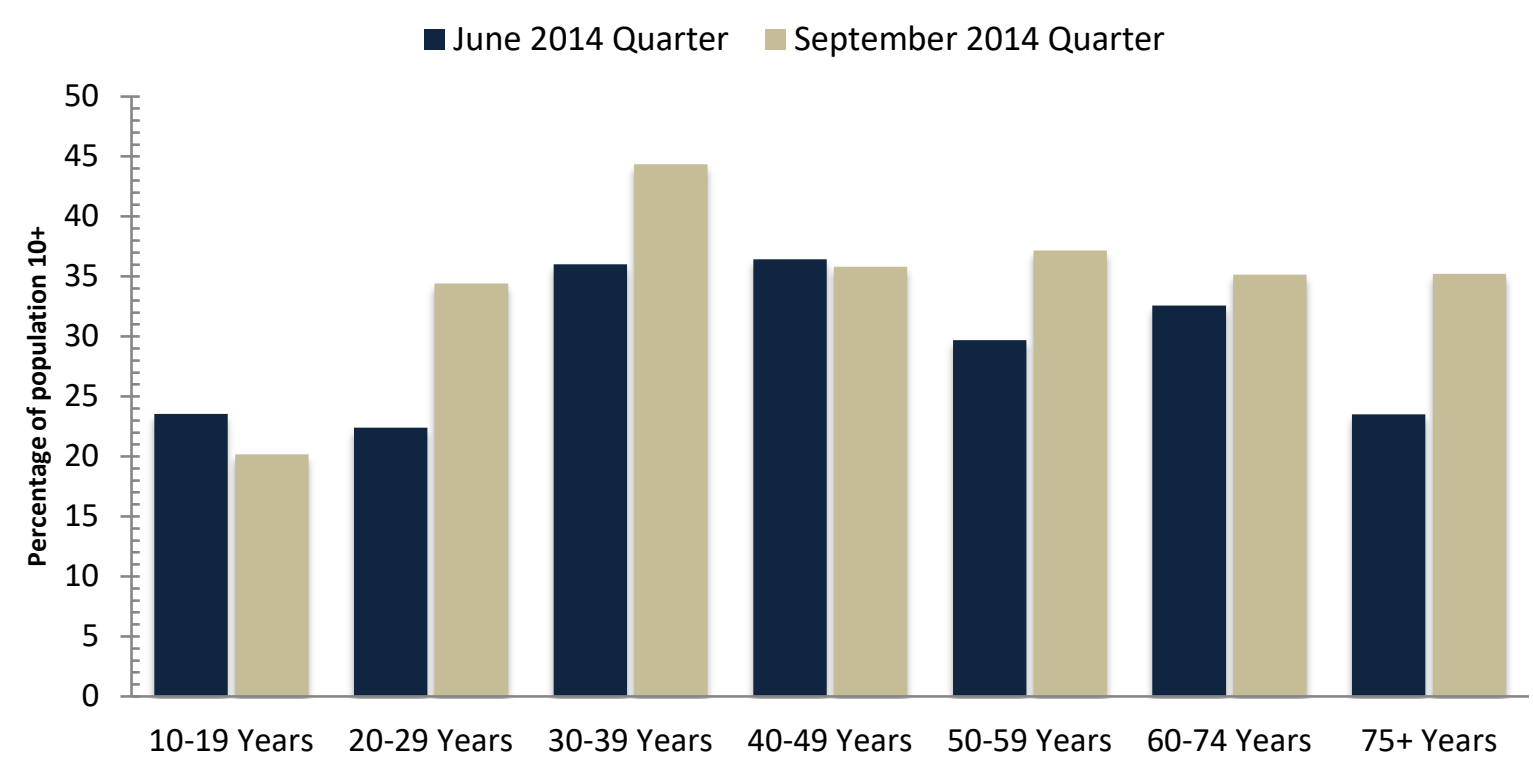

Figure: Age and Volunteering in New Zealand, 2014

Source - Statistics New Zealand: Volunteering New Zealand

Volunteering is a primary mechanism within civil society but is also inextricably connected with the political/economic sphere in which the dynamics of the market and government policies influence space for civil society contributions. To a significant degree, the need for volunteering at a societal level is because there may be inadequate funding from a government for social services for citizens and where private enterprise has a limited or no proper role.

It is important to acknowledge that the context in which older people volunteer and learn is complex and dynamic. For example, the reasons for involvement can be varied and changeable. The motivations for these volunteers are diverse - to use one's time productively; to contribute to local community development; to foster positive relationships with one's peers and/or across generations; to consciously build social networks at a time in life when social isolation can be very detrimental to one's well-being; to develop new knowledge and skills. These motivations mirror the dominant motives for adult learning more generally - while in later life most motives tend to be expressive, instrumental purposes can play a part also (Morstain \& Smart, 1974; Mezirow, 1981). The actual work undertaken can occur in very diverse settings. In New Zealand, a study of older people's volunteering revealed instances of business mentoring, community volunteering, Age Concern engagement (helping people to overcome life issues in later life), involvement in the Supergran service (one in which mature-aged women volunteer to work with disadvantaged people in communities) , in Māori (indigenous) institutions, and inter-generational exchange through (high) schools (Gee, 2001). Volunteers may operate from very informal roles (e.g. a coach for a soccer team) to much more formal (in tight organizational structures where regulations are enforced such as when volunteers are engaged in governance tasks). Milligan and Conradson (2006) add that voluntarism in health and welfare is prevalent where both volunteers and recipients are often in the older age group. In this regime the state-voluntary sector relationship is crucial to negotiate, given 
that increasingly expectations of volunteers for professionalization and managerialism accompany social change.

\section{Learning in the volunteer workplace}

Learning can take many forms in a continuum from informal to formal contexts. At an informal level, volunteers can develop considerable knowledge of work tasks on an experiential basis, coupled with more formalised training. For example, docents in a museum could learn how to effectively communicate with visitors and share their knowledge of exhibits acquired both through instructorled sessions/seminars but also through dialogue with visitors. Some of this learning will be selfdirected, as in undertaking further reading (Knowles, 1980); some of it will be developed on the job; some via specific training related to knowledge of exhibits.

While the volunteers are continuing learners, they are also workers. Hence, they are subject to regulations and constraints imposed by the employing authority and its context. Seniors as volunteers provide considerable flexibility for an organisation in relation to a dynamic workforce but they also present a special challenge for the continuity of services, given their ability to cease work at short notice. The relationship of volunteers to other workers (e.g. part-time paid, full-time salaried) is crucial for the strength of an agency and for the sustenance of the individual volunteer. In cases where the expertise of a volunteer is greater than that of a paid worker, the dynamics of relationships may be fraught (Beatty \& Visser, 2005).

\section{The perspective of an older adult volunteer}

For many volunteers the attraction of volunteering is multi-faceted. By definition, the volunteer has engaged in an active choice to provide free or cheap labour to an organisation. The extent of commitment is largely determined by the individual and engagement can be piecemeal or heavy. Volunteering in a particular context may be a continuation of previous life experiences (e.g. a retired accountant helps a social agency to be financially viable and accountable) or it may be in pursuit of an interest long postponed from earlier in life (e.g. a grandmother with a deferred interest in art history takes on the role of docent in an art gallery).

The expertise which an individual may bring to an agency may be manifest or latent. Retired professionals functioning in their usual domain of expertise would seldom be challenged in what they can offer; on the other hand, a person who has been in an earlier paid working class context may on the surface be more limited in the scope of tasks that are immediately transferable. This situation calls for fair and equitable recruitment strategies on the employer's part. The assumptions of both the individual and the employer need to be robustly tested to ensure a "goodness of fit" to tasks to be performed within an agency. Morrow-Howell (2010) argues that we need to move beyond the identification of personal characteristics to a fuller understanding of how previous life experience can be connected to volunteering "especially transitions in working and caregiving and changes in income, marital status, and health associated with later life. More nuanced understanding of what influences older adults to start, continue, or quit volunteering are important to organizations that depend on volunteers" (p.463).

In assessing the potential benefits of later life learning, the National Seniors Australia (NSA), supported by the Department of Health and Ageing of the Australian Government, conducted a 
study (2010) in which the economic, social and health benefits for older adults were identified. These same benefits can be associated with volunteering. In economic terms, the acquisition of skills and qualifications; increased financial literacy and knowledge - these were emphasised as either direct or indirect benefits. Socially, potential benefits were connecting with people with similar interests and the creation of social networks, both aspects of life which assume greater significance in later life (Findsen, 2005). In terms of health, improvements in health knowledge, improvements in physical health and wellbeing (including mental health) and greater cognitive performance were identified - these gains in turn often contribute to more life satisfaction. The volunteer role has the high prospect of accentuating productive ageing in comparison with other social roles. As noted by Horrow-Howell (2010), "volunteering is socially valued, publicly recognized, and more discretionary than working or caregiving" (p.465). It is an activity that can enhance social capital (Field, 2003) and help sustain a strong personal identity in later life.

From the volunteers' viewpoint, the circumstances of volunteering are often beneficial, but what kinds of issues emerge to challenge volunteers in their work? To answer this question, the domain of workforce development provides some explanations. Illeris (2011) discusses workplace activities and strategies, and refers to "elderly workers" as a special learner group wherein many experience the "life-turn", that is, "a psychological phenomenon implying a personal perception and acknowledgement that one's remaining lifetime is not unlimited' (p.152). In this state, older workers want their efforts and opinions to be respected and influential. When employers ignore this need, the likelihood is that the older worker/volunteer will give up the engagement.

In a similar way to Illeris's life-turn, Rothwell et al (2008) argue that many older adults are in a phase of the "protean career", that is, one in which the worker rather than the employing authority determines the work track. While this kind of career is more strongly linked to professionals, it is also prevalent among older people who have considerable expertise and economic security to pursue their life interests. Quite clearly, volunteering offers those older people following a protean career opportunities to largely choose what interests to accentuate and which agency may help meet this need.

One of the persistent myths concerning older workers/volunteers, is that they are either reticent to be further trained or that such training may be wasted (given uncertain longevity in the role). From

a lifelong learning framework, this is nonsensical thinking. The capacity of older adults to continue to learn is only partially related to ageing (physiological and cognitive decline is usually minimal). Older volunteers can become frustrated by employers' ignorance or discrimination related to further training opportunities (Beatty \& Visser, 2005). In general, should training be available (some social welfare agencies may be economically under strain and see staff development as a luxury), the majority of older volunteers are eager to participate. Some, perhaps internalizing the stereotype of incapacity to learn, may choose to minimise their training and thereby jeopardise their attachment to their voluntary work.

\section{The perspective of an employer of volunteers}

Given the plurality of motives for volunteers' engagement in an agency, it is imperative that an employer is really conversant with what motivates the individual volunteer. Such an understanding is likely to lead to better dialogue and longer-term commitment from the volunteer. Given that financial reward is not a direct motivator for volunteers, the astute employer may identify other 
reasons for volunteering, such as establishing social networks, as primary and establish work tasks accordingly.

A direct benefit of using older volunteers is economic sustenance of the organisation, admittedly based on uncertain foundations. Given the propensity for volunteers to vote with their feet if times get tough, it is prudent for employers to enhance the flexibility for volunteers and to involve them in decision-making to maximise commitment and ownership. It is imperative that fair and equitable human resource strategies are in operation and that the older volunteer not feel marginalised in the workforce. In relation to training opportunities, these need to be transparent and provided throughout all sectors of the workforce (unpaid/paid).

The importance of effective recruitment and retention strategies of volunteers should not be underestimated. Policies and practices should not inadvertently favour younger workers. Assumptions regarding the capabilities of older volunteers should be tested for their validity. For example, the belief that most/all older people are in need of training in Information and Communications Technologies (ICT) should be grounded in that agency's realities. Should this need arise, then strategic management of inter-generational mentoring programs may benefit both young and old in the organisation. Inter-generational learning programs in workplaces can readily enhance the quality of collegial relationships and breakdown prejudices based on age (Schmidt-Hertha et al, 2014).

Employers need to be cognisant of the previous experiences and knowledge which older volunteers can bring to their organisation. Recognition of prior learning (RPL) is a key mechanism by which employers may gauge and value the contribution of volunteers. Whether this learning has been acquired via self-directed activities, through membership of varied organisations beyond the work environment or through formalised training programmes is largely irrelevant. What is relevant is for employers to acknowledge the considerable life and work experiences which volunteers may bring to their agency and to capitalise on this expertise.

Rothwell et al (2008, pp.116-117)) have identified "learner characteristics" of older adults that they believe need to be taken into account when implementing learning opportunities. Amid their ten "key foundational principles", these authors refer to the following principles which have special implications for older volunteers as learners:

- Adults are problem-centred in how they regard learning experiences

- Gauging expectations before a learning event is critical

- Trainers should plan to provide feedback and recognition to learners

- Planned learning experiences should take into account adult lifespan development, needs and values

- Learning experiences should take into account ways to encourage on-the-job transfer

- Mature workers need a psychological supportive environment in which to learn.

While some of these principles can be disputed, the overall tone of the recommendations is that the current life circumstances and previous work environments of older workers/volunteers be seriously interrogated by employers. Some learning principles can be readily enacted by employers; others require on-going observation and monitoring to maximise their effect. 


\section{Concluding remarks}

This article has explored the connections between volunteering undertaken by older adults and the learning that may occur in this process. Given the varied contexts in which volunteering takes place, the kinds of learning can be diverse, either triggered by the volunteer or arranged by the employer. In some instances, informal learning predominates through a capitalising of prior experiential knowledge brought to the situation by the volunteer to the tasks of the job; equally, more formal opportunities may arise where specific training is identified by the volunteer and/or by the agency.

The incidence of volunteering in societies with an extensive civil society such as New Zealand is indeed high. While it is more likely that adults with higher educational credentials and considerable social capital are more likely to become volunteers (at least in organisations representing the interests of the dominant culture), it should not be assumed that working class people and those from ethnic minorities, for instance, do not volunteer. Their volunteering is probably less visible and more culturally appropriate, as exemplified by Māori in New Zealand whose volunteerism tends to be associated with culturally preferred practices.

A central purpose of this article has been to emphasise that volunteering can result in a "win-win" situation for both volunteer and voluntary bodies. Adult learning permeates the entire environment, if not in a training regime instigated by the employer then through individual volunteers assuming agency and expressing their learning needs more explicitly. In most instances, there is a power differential operating in favour of the voluntary body and employers. In terms of retention of enlightened elders as volunteers, there is a need to exercise considerable sensitivity to retain staff. Given that volunteers are normally not coerced into providing their expertise and free labour, the interactions between employer-employee need to be based on mutual trust and clarity of purpose.

For volunteers, participation may emerge from a variety of motives, usually disconnected with direct monetary reward. As McClusky (1974) has pointed out that contributive and influence learning needs tend to surface more strongly in later life. Lifelong learning themes of economic sustainability, the development of personal fulfilment, taking on a role as an active citizen and striving for an inclusive environment can all be manifested through a volunteering regime in an organisation. It is argued that these themes can best be understood and enacted in the dynamics of workplaces where enhancers and constraints for learning operate.

What are the implications for older learners as volunteers? Individual learners/volunteers need opportunities to expand their learning repertoire to meet the often escalating demands of organisations in a competitive marketplace. They should make more transparent what knowledge and skills can be used in the specific context of the voluntary organisation; when tasks require further training, then this needs to be made known to an employer; regardless of age, (unpaid) workers have a right to equal access to educational opportunity in the workplace.

On the other hand, agencies can better serve their own interests by co-operating with volunteers to contribute in many different ways. More initial engagement with prospective volunteers to understand their life experiences relevant to the job and their motives for contributing should be ascertained and periodically revisited as motives are often dynamic. Policy around training opportunities needs to be overt and strategies developed to ensure that rhetoric can readily be converted into practice. 
While there are explicit benefits for both older volunteers and their employing agencies, there are many challenges ahead for learning in later life to be maximised in organisational contexts. The location of older volunteers with respect to other (usually paid) workers and management is crucial related to the autonomy and responsibility assumed by them. In many instances, volunteers are placed in a marginalised position, as in access to appropriate training and other resources, but they can always walk away from service at short notice if circumstances become intolerable. However, usually both the volunteer and employing agency are looking for mutual benefit. 


\section{References}

Arber, S. \& Ginn, J. (1995). (Eds.) Connecting gender and aging: A sociological approach. Buckingham, UK: The Open University Press.

Beatty, P.T. \& Visser, R., M.S. (2005). (Eds.) Thriving on an Aging Workforce: strategies for organizational and Systemic Change. Malabar, Florida: Kreiger Publishing Co.

Beck, U. (1992). Risk society: towards a new modernity. London: Sage.

Bourdieu, P. (1974). The school as a conservative force. In J. Eggleston (Ed) Contemporary research in the sociology of education (pp.32-46). London: Metheuen.

Casey, C. (1999). The changing contexts of work. In D. Boud \& J. Garrick (Eds.) Understanding learning at work, pp.15-28. London: Routledge.

Field, J. (2003). Social capital. London: Routledge.

Field, J. (2000). Lifelong learning and the new educational order. Stoke on Trent: Trentham Books.

Formosa, M. (2000). Older adult education in a Maltese University of the Third Age: A critical perspective. Education and Ageing, 15(3), 315-339.

Findsen, B. (2014). Developing a "win-win" scenario: Understanding how older workers' learning can be enhanced within organisations, in T. Short \& R. Harris (Eds). Workforce development: Strategies and practices, pp.59-73. Singapore: Springer.

Findsen, B. (2006). Social institutions as sites of learning for older adult: Differential opportunities, Journal of Transformative Education, 4 (1), 65-81.

Findsen, B. (2005). Learning later. Malabar, Florida: Krieger Publishing Co.

Findsen, B. \& Formosa, M. (2011). Lifelong learning in later life: a handbook on older adult learning. Rotterdam: Sense Publishers.

Formosa, M. (2000). Older adult education in a Maltese University of the Third Age: A critical perspective. Education and Ageing, 15 (3), 315-339.

Gee, S. (2001). (Ed.) Experience of a lifetime: Older New Zealanders as volunteers. Wellington: Victoria University of Wellington.

Illeris, K. (2011). The fundamentals of workplace learning: Understanding how people learn in working life. London: Routledge.

Jarvis, P. (2001). Learning in later life: An introduction for educators and carers. London: Kogan Page Ltd.

Knowles, M.S. (1980). The modern practice of adult education: From pedagogy to andragogy. Cambridge: The Adult Education Company. 
Lamdin, L. \& Fugate, M. (1997). Elderlearning: New frontier in an aging society. Phoenix Arizona: American Council on Education \& Oryx Press.

Laslett, P. (1989). A fresh map of life: The emergence of the third age. London: Weidenfeld \& Nicholson.

McClusky, H.Y. (1974). Education for aging: the scope of the field and perspectives for the future. In Grabowski, S. \& Mason, W.D. (Eds.) Learning for aging. Washington, D.C.: Adult Education Association of the USA.

Mezirow, J. (1981). A critical theory of adult learning and education, Adult Education, 32 (1), 3-24.

Milligan, C. \& Conradson, D. (2006). (Eds) Landscapes of voluntarism: new spaces in health, welfare and governance. Bristol: The Policy press.

Morrow-Howell, N. (2010). Volunteering in later life: Research frontiers, Journal of Gerontology: Social Sciences, 65B (4), 461-469.

Morstain, B.R. \& Smart, J.C. (1974). Reasons for participation in an adult education course: A multivariate analysis of group differences, Adult Education, 24 (2), 461-469.

National Seniors Australia (2010) Later life learning: Unlocking the potential for productive ageing. Australian Government: Department of Health and Ageing. Braddon, ACT: NSA Productive Ageing Centre.

Putnam, R.D. (1995). Bowling alone: America's diminishing social capital. Journal of Democracy, 6 (1), 65-78.

Riley, M.W. \& Riley J. Jr (1994). Age integration and the lives of older people. The Gerontologist, 34 (1), 110-115.

Rothwell, W.J., Sterns, H.L., Spokus, D., \& Reaser, J.M. (2008). Working longer: New strategies for managing, training, and retaining older employees. New York: American Management Association.

Phillipson, C. (2013). Ageing. Cambridge: Polity Press.

Phillipson, C. (1998). Reconstructing old age: New agendas in social theory and practice. London: Sage Publications.

Schmidt-Hertha, B.S., Krasovec, S.J. \& Formosa, M. (2014). (Eds.) Learning across generations in Europe: Contemporary issues in older adult education. Rotterdam: Sense Publishers.

Statistics New Zealand (13 August 2013). New Zealand General Social survey: 2012. Ministry of Internal Affairs.

Statistics New Zealand. (2014). Volunteering in New Zealand.

http://www.volunteeringnz.org.nz/policy/statistics. Accessed on 11 October, 2015.

Swindell, R. (2000). Half a million dollars a year: Voluntarism within New Zealand Universities of the Third Age, New Zealand Journal of Adult Learning, 28 (1), 23-31. 
Tett, L. (2010) (3rd ed.) Community education, learning and development. Edinburgh: Dunedin Academic Press Itd.

Tuckett, A. \& McAulay, A. (2005). (Eds.) Demography and older learners: Approaches to a new policy challenge. Leicester: National Institute of Adult Continuing Education.

Welton, M. (2005). Designing the just society: A critical enquiry. Leicester: NIACE. 